\title{
Development of High-Throughput SNP Genotyping Assays for Rapid Detection of Strawberry Colletotrichum Species and the G143A Mutation
}

\author{
Bruna B. Forcelini, Seonghee Lee, Michelle S. Oliveira, and Natalia A. Peres ${ }^{\dagger}$
}

Gulf Coast Research and Education Center, University of Florida, Wimauma 33598.

Accepted for publication 9 July 2018.

\begin{abstract}
Colletotrichum spp. cause major diseases of strawberry and disease management depends on the species present. However, species identification based on symptoms and spore morphology is difficult. Therefore, development of molecular techniques for trustworthy and high-throughput identification of Colletotrichum spp. is vital for the accurate diagnosis. A high-resolution melting (HRM) assay was developed for simultaneous identification and differentiation of Colletotrichum spp. from fungal colonies or from symptomatic strawberry tissue. HRM markers were designed based on the internal transcribed spacer region of Colletotrichum
\end{abstract}

ABSTRACT acutatum and C. gloeosporioides from strawberry, and accurately identified and differentiated the two species. In addition, for the rapid detection of a single-nucleotide polymorphism (SNP) in the cytochrome $b(c y t b)$ gene of $C$. acutatum and $C$. gloeosporioides associated with resistance to quinoneoutside inhibitor fungicides, an endpoint SNP genotyping analysis was developed. The HRM and endpoint SNP genotyping assays are useful methods that can be implemented in plant diagnostic clinics for the rapid and accurate identification of Colletotrichum spp. and detection of the G143A mutation in the cytb gene of $C$. acutatum and C. gloeosporioides.
Species in the Colletotrichum acutatum and C. gloeosporioides species complexes are cosmopolitan pathogens, causing anthracnose on a wide range of hosts (Damm et al. 2012; Weir et al. 2012). On strawberry, anthracnose incidence may exceed $50 \%$ when disease control measures are not applied in a timely fashion and environmental conditions are conducive for infection (Legard et al. 2003; Mertely et al. 2015). Characteristic symptoms of C. acutatum infections are flower blight; fruit rot, typical of anthracnose fruit rot (AFR); and root and crown necrosis, typical of anthracnose root necrosis. However, AFR is the most detrimental for crop yield, because symptomatic fruit are not appealing for human consumption (Mertely et al. 2017a; Mertely et al. 2017b; Peres et al. 2005).

$C$. gloeosporioides and $C$. fragariae cause virtually identical symptoms and $C$. fragariae is considered part of the $C$. gloeosporioides species complex (Weir et al. 2012). Both species are pathogenic to strawberry and infections can result in crown necrosis that leads to plant wilting and, eventually, plant death (Peres et al. 2017; Smith 1998b). In addition to crown rot, C. gloeosporioides and $C$. fragariae are also capable of infecting strawberry fruit, causing symptoms of AFR (Peres et al. 2017; Smith 1998b). The ability of C. acutatum, C. gloeosporioides, and C. fragariae to infect the same strawberry tissues and produce similar symptoms have caused confusion in the identification of the causal agent (Mertely et al. 2017b; Smith 1998a,b). Accurate and rapid identification of the causal agent is instrumental for the development of effective disease management practices, because cultural and chemical control methods can be specific according to the Colletotrichum sp.

Colletotrichum spp. management is based primarily on applications of single- and multisite fungicides (Mertely et al. 2017a,b; Peres et al. 2017). Single-site fungicides with curative activity such as the quinone-outside inhibitors (QoI) have been extensively used to control Colletotrichum spp. (Mertely et al. 2017a,b; Peres et al. 2017; Turechek et al. 2006). QoI are respiration-inhibitor

${ }^{\dagger}$ Corresponding author: Natalia A. Peres; E-mail: nperes@ufl.edu

Funding: This research was partially supported by the Florida Strawberry Research and Education Foundation and the National Institute of Food and Agriculture, United States Department of Agriculture under award number 2014-51181-22377.

(C) 2018 The American Phytopathological Society fungicides that are used to disrupt the fungus energy cycle by inhibiting mitochondrial respiration (Bartlett et al. 2002). Mutations present in the cytochrome $b(c y t b)$ gene have been associated with QoI resistance. The most commonly observed, G143A, is a result of the replacement of glycine by alanine at codon 143 . Isolates that harbor such a mutation are known to be completely resistant (Gisi et al. 2002).

QoI resistance in C. acutatum isolates of strawberry was first reported in 2013 in Florida production fields and subsequently in nurseries and commercial fields across the United States and Canada (Forcelini and Peres 2016; Forcelini et al. 2016). The majority of the resistant isolates harbored the G143A mutation and were completely resistant to QoI. Moreover, C. gloeosporioides resistance to QoI fungicides was also first detected in Florida during the 2015-16 season (Oliveira et al. 2016). The detection of QoIresistant populations in strawberry nurseries and production fields is a significant component of disease management programs because QoI fungicides are not recommended to be used in fields with QoI-resistant profiles (Forcelini et al. 2016, 2018). Currently, detection of isolates with reduced sensitivity to QoI fungicides requires laborious and time-consuming in vitro and in vivo assays such as conidial germination and fruit assays, respectively. In addition, identification of mutations associated with QoI resistance require sequencing or restriction enzyme analyses of the $c y t b$ gene (Forcelini et al. 2016, 2018).

Identification of Colletotrichum spp. is generally based on ecological and morphological characteristics, such as size and shape of conidia, pigmentation, and growth rate of fungal colonies (Damm et al. 2012; Grahovac et al. 2012; Smith and Black 1990). However, morphological features may vary with environmental conditions, and overlap between species has been reported (Damm et al. 2012; Van der Aa et al. 1990). Thus, the use of molecular marker techniques is an instrumental compliment for accurate identification and differentiation of Colletotrichum spp. (Damm et al. 2012; Grahovac et al. 2012; Weir et al. 2012). Species-specific polymerase chain reaction (PCR) primers for C. acutatum and C. gloeosporioides were designed by Sreenivasaprasad et al. (1996) from the internal transcribed spacer (ITS) region of ribosomal DNA gene and used by Grahovac et al. (2012). Primer CgInt amplifies a 450-bp fragment of C. gloeosporioides and C. fragariae, whereas primer CaInt amplifies 
a 490-bp fragment of C. acutatum (Grahovac et al. 2012). However, this conventional gel-based marker method is time consuming and labor intensive for large numbers of samples, because two separate PCR assays have to be performed, each using either the CgInt or CaInt primer (Grahovac et al. 2012).

The high-resolution melting (HRM) assay is a powerful and costeffective methods for mutation scanning and single-nucleotide polymorphism (SNP) genotyping. This PCR-based method identifies genetic variations in DNA sequences based on its melting curve profiles (Reed et al. 2007). Differences in melting curve profiles can be a result of differences in the genotype such as PCR amplicon length, GC content, sequence, and heterozygosity (Reed et al. 2007; Vossen et al. 2009). This genotyping technique has been widely used for genetic studies in humans for over a decade and, more recently, applied for numerous plant breeding program due to its simplicity, accuracy, reproducibility, and low-cost (Gopaul et al. 2014; Taheri et al. 2017). Recently, HRM analysis has been essential for identification and differentiation of plant pathogens, detection of mutations associated with fungicide resistance, and identification of important traits for marker-assisted breeding in crops (Chatzidimopoulos et al. 2014; Lehner et al. 2015; Noh et al. 2017; Papavasileiou et al. 2016; Samaras et al. 2016; Summers et al. 2015).

Although the HRM analysis has been successful in detecting resistance to fungicides in plant pathogens (Chatzidimopoulos et al. 2014; Samaras et al. 2016), another probe-based genotyping method, called endpoint SNP genotyping or TaqMan assay, may be preferred for genotyping large populations and highthroughput genotyping platforms (Rasheed et al. 2017; Shen et al. 2009). Because endpoint SNP genotyping is simple, fast, and an automated genotyping method, this method can be ideal for detection of specific SNP associated with fungicide resistance in large populations of plant pathogens. Similar to the HRM, this is a closed-tube method, where the region of a gene of interest is amplified by PCR (Shen et al. 2009). PCR primers are required for amplification of a specific locus on the genomic DNA, while labeled probes hybridize to its associated allele in the DNA template (De la Vega et al. 2005). Such probes may hybridize to DNA strands where target SNP may or may not be present. Despite the wide application of this methodology in human genetics research and plant breeding (Shen et al. 2009), the application of the endpoint SNP genotyping in plant pathology is still in its infancy.

With the goal to provide strawberry growers with fast and accurate information about disease diagnosis and pathogen resistance to the QoI fungicides, the objectives of this study were to (i) develop and validate an HRM analysis to detect and differentiate Colletotrichum spp. pathogenic to strawberry, (ii) develop and validate an endpoint SNP genotyping analysis to detect the G143A mutation in the $c y t b$ gene of $C$. acutatum and $C$. gloeosporioides isolates of strawberry, and (iii) perform a rapid detection of Colletotrichum DNA directly from strawberry plant tissues using the HRM and endpoint SNP genotyping analyses.

\section{MATERIALS AND METHODS}

Fungal cultures and DNA extraction. In all, 50 C. acutatum, 25 C. gloeosporioides, and 16 C. fragariae isolates collected from 1994 to 2016 from anthracnose-affected strawberry plants were included in this study. Symptomatic strawberry tissue originated from nurseries and commercial fields from Florida, California, Georgia, Louisiana, and North Carolina. Species identification was based on cultural, morphological, and (in some cases) genetic characterization (MacKenzie et al. 2009). Isolates were single spored and maintained on filter paper in a sterile envelope in an airtight container with Drierite (W. A. Hammond Drierite Company, Ltd.) at $-20^{\circ} \mathrm{C}$ or in $20 \%$ glycerol at $-80^{\circ} \mathrm{C}$. Seven days prior to DNA extraction, isolates were revived on potato dextrose agar (PDA) and grown at room temperature (approximately $24^{\circ} \mathrm{C}$ ) under constant light. For DNA extraction, $100 \mathrm{mg}$ of mycelia were harvested and extraction was performed using the FastDNA Kit (MP Biomedicals). DNA was quantified by a nanodrop spectrophotometer and diluted to a final concentration of $25 \mu \mathrm{g} / \mathrm{ml}$. Diluted DNA was stored at $-20^{\circ} \mathrm{C}$ until further use.

HRM analysis. Two HRM markers, AcGl-F1 and AcGl-R1 (Table 1), were designed based on the ITS sequences of $C$. acutatum and $C$. gloeosporioides using the Integrated DNA TechnologiesPrimerQuest tool with the option of quantitative PCR intercalating dye (https://www.idt.com/). The primer set was used to amplify a 187-bp product located in the ITS gene. PCR amplification and HRM analysis were performed in a total volume of $10 \mu \mathrm{l}$ on the LightCycler 480 system II (Roche Life Science). Each reaction contained $5 \mu$ l of $2 \times$ AccuStart II PCR ToughMix (QuantaBio), $0.5 \mu \mathrm{l}$ of $10 \mu \mathrm{M}$ each forward and reverse primers, $0.5 \mu \mathrm{l}$ of $10 \times$ LCGreen Plus+ (BioFire Defense), $2.5 \mu$ l of molecular water, and $1 \mu \mathrm{l}$ of a 25 -ng genomic DNA template, and was placed in a 384-well plate (LightCycler 480 Multiwell Plate 384, White). PCR amplification was conducted using the following conditions: preincubation at $95^{\circ} \mathrm{C}$ for $3 \mathrm{~min}$, followed by 35 cycles of denaturation at $95^{\circ} \mathrm{C}$ for $20 \mathrm{~s}$, annealing at $60^{\circ} \mathrm{C}$ for $30 \mathrm{~s}$, and extension at $72^{\circ} \mathrm{C}$ for $40 \mathrm{~s}$. For post PCR amplification, samples were exposed to the following HRM conditions: $95^{\circ} \mathrm{C}$ for $1 \mathrm{~min}$, $40^{\circ} \mathrm{C}$ for $1 \mathrm{~min}, 65^{\circ} \mathrm{C}$ for $1 \mathrm{~s}$, and $95^{\circ} \mathrm{C}$ continuous. At the last step, samples were cooled at $40^{\circ} \mathrm{C}$ for $30 \mathrm{~s}$. Melting curves of each sample were analyzed using the LightCycler 480 system II melting curve software. Experiments were conducted in triplicate.

To examine assay sensitivity, an HRM analysis was performed using different concentrations of C. acutatum DNA to determine the detection limits of the AcGl-F1 and AcGl-R1 markers. Serial dilutions of $C$. acutatum resulting in $0.000001,0.00001,0.0001,0.001$, 0.01 , and $1 \mathrm{ng}$ per reaction tube were analyzed using the HRM assay.

Plant sampling and DNA extraction. Strawberry crowns. During the 2017-18 Florida strawberry season, 467 strawberry plant samples received at the University of Florida-Gulf Coast Research and Education Center Plant Diagnostic Clinic were processed. Plants showing symptoms of wilt and stunting were washed to remove soil debris and crowns were cut in half vertically.

TABLE 1. List of primers and probes designed for this study

\begin{tabular}{|c|c|c|}
\hline Analysis method $^{\mathrm{a}}$ & Primer or probe & Sequence \\
\hline HRM & AcGl-F1 & CCTGTTCGAGCGTCATTTC \\
\hline HRM & AcGl-R1 & GGTCCGCCACTACCTTT \\
\hline Endpoint SNP Genot. & Ca_QoI_F1 & GGGTATAGGTTTCCTGGGTTATG \\
\hline Endpoint SNP Genot. & Ca_QoI_R1 & TCCAATTCAAGGGATAGCACTTAT \\
\hline Endpoint SNP Genot. & Ca-S-FAM & ACTGTTGCACCTCATAATGACATTTGTCC \\
\hline Endpoint SNP Genot. & Ca-R-HEX & ACTGTTGCAGCTCATAATGACATTTGTCC \\
\hline Endpoint SNP Genot. & Cg_QoI_F1 & TTACCTTACGGGCAAATGT \\
\hline Endpoint SNP Genot. & Cg_QoI_R1 & CTCAACGATATCTTGTCCAATTC \\
\hline Endpoint SNP Genot. & Cg-S-HEX & TGAGGTGCAACAGTTATTACTAACCT \\
\hline Endpoint SNP Genot. & Cg-R-FAM & TGAGCTGCAACAGTTATTACTAACCT \\
\hline
\end{tabular}

${ }^{\mathrm{a}} \mathrm{HRM}=$ high-resolution melting and Endpoint SNP Genot = endpoint single-nucleotide genotyping. 
If reddish-brown necrotic areas were observed in the interior of the crown tissue, these were removed and assayed using the HRM assay and common diagnostic isolation techniques. Half of the necrotic tissue was assayed using the HRM, while the other half was divided into four $1-\mathrm{mm}^{3}$ pieces and plated on PDA amended with streptomycin at $0.1 \mathrm{~g} /$ liter and ampicillin at $0.25 \mathrm{~g} /$ liter. Identification of the causal agent based on morphological and ecological features was confirmed 3 to 4 days later. For the HRM analysis, approximately $0.5 \mathrm{~g}$ of symptomatic crown tissue was used for DNA extraction following the protocol published by Miles et al. (2015), and PCR and post-PCR conditions were performed as described above. Results of the diagnosis obtained from the HRM analysis and standard general diagnostic procedure were compared to validate the HRM assay.

Detached fruit. Immature fruit of cultivar Florida Beauty that had a receptacle with chlorophyll were harvested from the University of
Florida Gulf Coast Research and Education Center experimental plots. Sepals were removed and fruit were surface disinfested in $0.7 \%$ sodium hypochlorite $(\mathrm{NaClO})$ for $6 \mathrm{~min}$. $\mathrm{NaClO}$ residue was removed by rinsing fruit with sterile autoclaved water four times for $30 \mathrm{~s}$ each time. Fruit were placed on clean egg cartons inside plastic boxes, and surface dried for $20 \mathrm{~min}$ under a fume hood. Inoculum suspensions for one $C$. acutatum (13-139), one $C$. gloeosporioides (16-448), and one $C$. fragariae (05-104) isolate were prepared by gently scraping 7-day-old fungal colonies with $1 \mathrm{ml}$ of sterile autoclaved water. Suspensions were filtered through a doublelayered cheesecloth and adjusted to $1 \times 10^{6}$ conidia $/ \mathrm{ml}$ using a hemocytometer. Eight fruit were inoculated with a $20-\mu$ droplet of the following species combinations: C. acutatum, C. gloeosporioides, $C$. fragariae, $C$. acutatum $+C$. gloeosporioides, C. acutatum $+C$. fragariae, C. gloeosporioides $+C$. fragariae, or C. acutatum + C. gloeosporioides $+C$. fragariae. To maintain high levels of

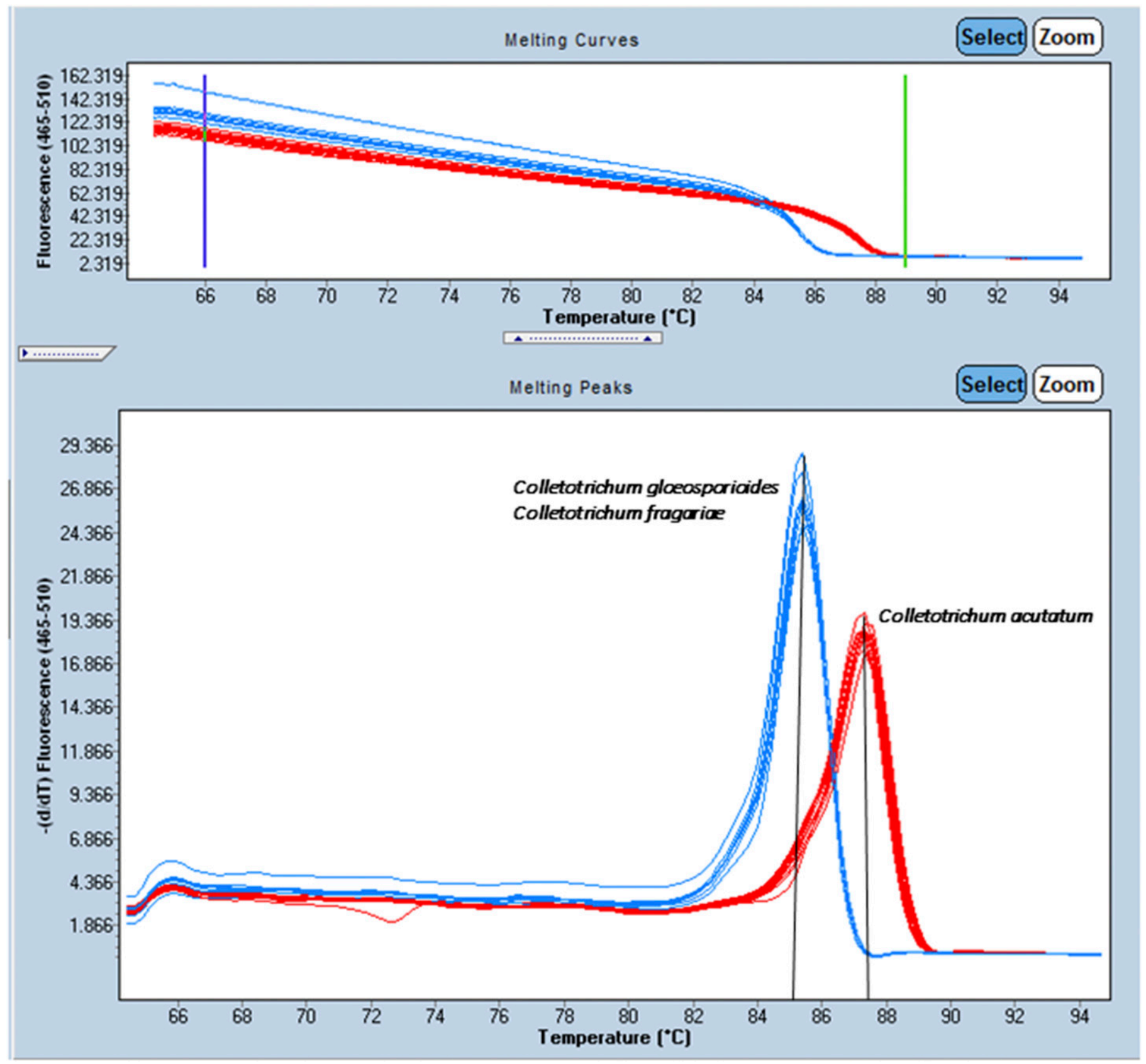

Fig. 1. High-resolution melting (HRM) analysis using the AcGl-F1 and AcGl-R1 markers for the identification and differentiation of Colletotrichum acutatum (darker) from C. gloeosporioides and C. fragariae (lighter) of strawberry. HRM produced two profiles of melting curve variance for $C$. gloeosporioides and $C$. fragariae, and for C. acutatum in aligned (upper panel) and derivative plot (bottom panel) analyses. 
humidity inside the boxes, $100 \mathrm{ml}$ of deionized water was placed inside each box. Boxes were then closed and placed under constant light at $24^{\circ} \mathrm{C}$ until anthracnose symptoms were observed. Spores from symptomatic fruit were gently collected with the aid of a pipette tip and placed in wells of a 384-well plate containing the HRM reagents. DNA of $C$. acutatum and $C$. gloeosporioides isolates that had been previously extracted with the FastDNA Kit were included in the analysis as positive controls. HRM analysis was conducted as described above.

Genotyping for the cytb gene of isolates of Colletotrichum spp. All 50 C. acutatum and 25 C. gloeosporioides isolates included in the endpoint SNP genotyping analysis had been previously evaluated for azoxystrobin sensitivity (Forcelini et al. 2016; Oliveira et al. 2016). The $c y t b$ genes of nine C. acutatum isolates were previously sequenced and either the F129L or G143A mutation was detected in QoI-resistant isolates (Forcelini et al. 2016). Analysis of the cytb gene of $11 \mathrm{C}$. gloeosporioides isolates was performed using the primers Cg-cytbF3 (ATCGCCTTGGTCTTACTACTATCG) and Detect-R1 (CATGGTTATATATCCTTTTGGTG), with PCR conditions as previously described by $\mathrm{Hu}$ et al. (2015). PCR product amplification was assessed by electrophoresis in a $1 \%$ agarose gel with $1 \times$ Tris-acetate-EDTA buffer $(40 \mathrm{mM}$ Tris-acetate and $0.1 \mathrm{mM}$ EDTA buffer) $+2.5 \mu \mathrm{l}$ GelRed (Biotium). Purification and sequencing of PCR products were performed by Genewiz Inc., and sequence alignment was conducted using the MEGA software (https://www.megasoftware.net/).

Endpoint SNP genotyping analysis. An endpoint SNP genotyping method was developed to rapidly and accurately detect the G143A mutation in the cytb gene in strawberry $C$. acutatum and C. gloeosporioides isolates. Partial sequences of the $c y t b$ gene of QoI-sensitive and -resistant $C$. acutatum and C. gloeosporioides were used to design endpoint SNP genotyping markers and the 6FAM- and HEX-labeled probes (Table 1) for the detection of the G143A mutation. Sequences of $C$. acutatum were deposited in GenBank under accession numbers MF784585 and MF784587, and of C. gloeosporioides under accession numbers MH193000, MH193001, MH193002, and MH193003. Markers and probes were designed using the Integrated DNA Technologies-PrimerQuest tool (https://www.idt.com/). The sets of primers Ca_QoI_F1 and Ca_QoIR1, and Cg_QoI_F1 and Cg_QoI_R1, were designed to amplify a 100 -bp fragment in the cytb gene of $C$. acutatum and $C$. gloeosporioides isolates, respectively. The addition of the probe HEX was used to detect fragments that harbor the G143A mutation, while the probe FAM was used to detect wild-type $C$. acutatum isolates. Conversely, in the case of $C$. gloeosporioides, the mutant allele-specific primer was labeled with FAM dye and used to detect the mutant, whereas the wild-type allele-specific primer labeled with HEX dye was used to detect the wild-type sequence. PCR assays were performed on a LightCycler 480 system II. Typical reactions contained $5 \mu \mathrm{l}$ of $2 \times$ AccuStart II PCR ToughMix (QuantaBio), $0.25 \mu \mathrm{M}$ each primer (forward and reverse) $0.1 \mu \mathrm{M}$ each probe (FAM and HEX), and $1 \mu \mathrm{l}$ of purified DNA or spores in a total volume of $10 \mu$ l. Cycling conditions were as follows: preincubation at $94^{\circ} \mathrm{C}$ for $3 \mathrm{~min}$, followed by 45 cycles of denaturation at $94^{\circ} \mathrm{C}$ for $10 \mathrm{~s}$, annealing at $62^{\circ} \mathrm{C}$ for $15 \mathrm{~s}$, and extension at $72^{\circ} \mathrm{C}$ for $5 \mathrm{~s}$. Samples were then cooled at $40^{\circ} \mathrm{C}$ for $30 \mathrm{~s}$. The increase in fluorescence due to complementarity of the probe to the sequence during the PCR was analyzed using the LC480 software

TABLE 2. Number of strawberry crown samples tested positive for Colletotrichum acutatum, C. gloeosporioides, and other pathogens using the highresolution melting (HRM) analysis and standard diagnosis procedures

\begin{tabular}{lccc}
\hline & \multicolumn{3}{c}{ Number of samples } \\
\cline { 2 - 4 } Pathogen & HRM & Standard diagnosis & Both positive \\
\hline C. acutatum & 10 & 18 & 5 \\
C. gloeosporioides & 119 & 79 & 79 \\
Other pathogens & $\ldots$ & 125 & $\ldots$ \\
\hline
\end{tabular}

for endpoint genotyping analysis. Experiments were conducted in triplicate.

Rapid detection of the G143A mutation directly from inoculated strawberry fruit. Inoculum and fruit were prepared as described above. Wild-type (3-32) and QoI-resistant (13-139) isolates harboring the G143A mutation in the $c y t b$ gene of C. acutatum were used in this trial. Twelve immature fruit were inoculated with $20 \mu \mathrm{l}$ of each of the following treatments: wild-type, QoI-resistant, and wild-type + QoI-resistant. Inoculated fruit were incubated as described above and monitored for anthracnose symptom appearance. Spores from symptomatic tissue were gently removed using a $10-\mu$ pipette tip and placed in wells of a 384-well plate containing the PCR for the endpoint SNP genotyping assay. In addition, purified DNA from wild-type and QoI-resistant isolates that had been previously extracted using the FastDNA Kit were included in the analysis as positive controls. Endpoint SNP genotyping assay and data analysis were performed as described above.

\section{RESULTS}

HRM analysis for the identification and differentiation of Colletotrichum spp. The primer set AcGl-F1 and AcGl-R1 accurately identified and differentiated C. acutatum from C. gloeosporioides and $C$. fragariae. Two unique melting curve profiles were generated using the primer set showing $2^{\circ} \mathrm{C}$ difference between the curve melting peaks. The melting temperature (Tm) of C. gloeosporioides and C. fragariae isolates was approximately $85^{\circ} \mathrm{C}$, whereas the melting Tm of $C$. acutatum isolates was approximately $87^{\circ} \mathrm{C}$ (Fig. 1). Ten-fold serial dilutions of DNA samples were done to determine the sensitivity or detection limit of the HRM assay; the HRM marker set substantially detected the target sequence to a concentration as low as $0.001 \mathrm{ng}$ of $C$. acutatum purified DNA.

Rapid detection of Colletotrichum spp. directly from strawberry tissues. The HRM assay successfully identified the different species of Colletotrichum from DNA extracted directly from symptomatic strawberry plant tissue. In crown tissue, among the 467 plant samples displaying symptoms of Colletotrichum crown rot, 10 tested positive for $C$. acutatum, whereas 119 tested positive for $C$. gloeosporioides with the HRM analysis. Standard diagnosis resulted in 18 and 79 samples positive for $C$. acutatum and C. gloeosporioides, respectively. Of the 18 positive for $C$. acutatum, only 5 tested positive with the HRM assay. For C. gloeosporioides, all of the 79 samples also tested positive with the HRM assay (Table 2). In detached fruit, the HRM analysis using the primer set AcGl-F1 and AcGl-R1 produced different melting curve profiles for C. acutatum, C. gloeosporioides, and C. fragariae, and for infections containing mixed DNA (Fig. 2). The HRM assay result with the purified DNA of $C$. acutatum was identical to spore samples from fruit inoculated with $C$. acutatum. The HRM melting curves of spores from fruit inoculated with $C$. gloeosporioides or C. fragariae were representative of $C$. gloeosporioides purified DNA. In mixed inoculations of C. acutatum, C. gloeosporioides, or $C$. fragariae, a melting curve with two peaks was observed, one peak characteristic of $C$. acutatum and another characteristic of C. gloeosporioides or C. fragariae.

Sequence analysis of cytb gene of $C$. gloeosporioides isolates. The primer pair $\mathrm{Cg}$-cytbF3/Detect-R1 amplified $c y t b$ gene fragments of $568 \mathrm{bp}$ of the $11 \mathrm{C}$. gloeosporioides isolates included in this study. Partial sequencing of the $c y t b$ gene of 11 C. gloeosporioides isolates revealed one amino acid substitution at codon 143 (Fig. 3). The replacement of glycine (G) by alanine (A) was observed in six QoI-resistant isolates (e.g., isolate 10-110 and 16-440), whereas the other five (QoI-sensitive) retained the glycine amino acid (e.g., isolate 96-85D and 16-450).

Endpoint SNP genotyping for the detection of the G143A mutation in $\boldsymbol{c y t} \boldsymbol{t}$ genes. The endpoint SNP genotyping analysis reliably identified wild-type $C$. acutatum and $C$. gloeosporioides genotypes from those isolates retaining the G143A mutation in the 
$c y t b$ gene. Genotypes for the wild-type or the mutant isolates were separated based on the fluorescence emitted by FAM or HEX dye after its hybridization to fragments of amplified wild-type or mutated DNA. Among the 50 C. acutatum isolates included in this study, the G143A mutation was detected in 22 isolates, whereas the other 28 were considered wild-type genotypes. The fluorescence resulting from the hybridization of the HEX probe to mutant C. acutatum isolates was detected in a range of 533 to $580 \mathrm{~nm}$, while fluorescence resulting from FAM and wild-type isolate hybridization was detected in a range of 465 to $510 \mathrm{~nm}$ (Fig. 4). For

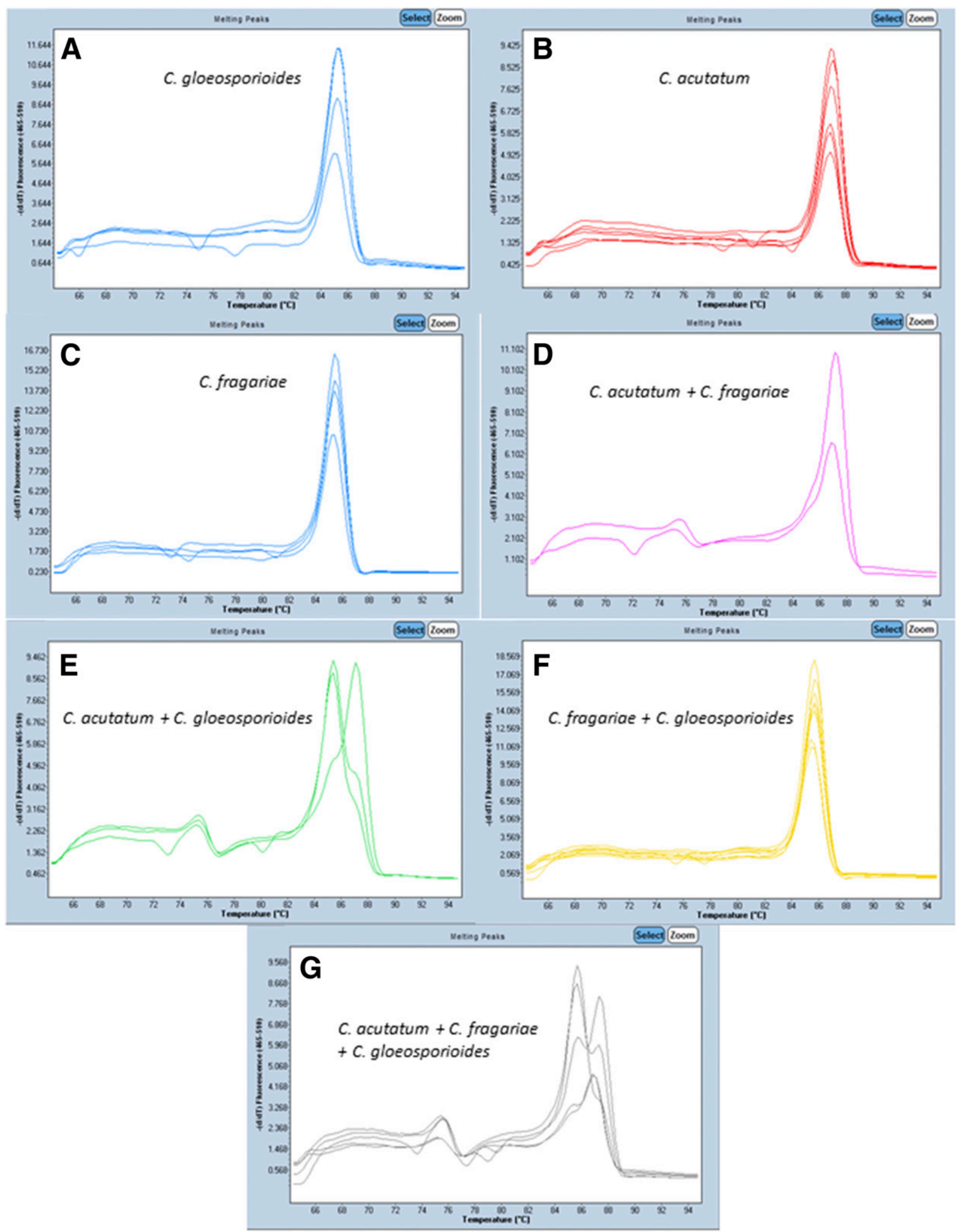

Fig. 2. High-resolution melting (HRM) analysis using the AcGl-F1 and AcGl-R1 markers for the identification and differentiation of A, Colletotrichum gloeosporioides; B, C. fragariae; and $\mathbf{C}, C$. acutatum from the crude DNA samples extracted directly from artificially inoculated strawberry fruit. $C$. acutatum inoculum $\left(1 \times 10^{6}\right.$ conidia/ml $)$ was mixed in a 1:1 ratio with inoculum from $C$. gloeosporioides or $C$. fragariae. The HRM assay produced different profiles of melting curves according to the following mixtures of Colletotrichum spp.: D, C. acutatum and C. fragariae; E, C. acutatum and C. gloeosporioides; $\mathbf{F}$, C. fragariae and C. gloeosporioides; and $\mathbf{G}$, C. acutatum, C. fragariae, and C. gloeosporioides DNA. 
C. gloeosporioides, the endpoint SNP genotyping assay detected the presence of the G143A mutation in only 8 of 25 isolates. Of the remaining 17 C. gloeosporioides isolates, 16 did not harbor the G143A mutation, and no DNA amplification occurred for one isolate. The fluorescence resulting from the hybridization of the FAM-labeled probe to mutant $C$. gloeosporioides isolates was detected in a range of 465 to $510 \mathrm{~nm}$, whereas fluorescence resulting from HEX and wild-type isolate hybridization was detected in a range of 533 to $580 \mathrm{~nm}$.

Rapid detection of the G143A mutation in the $c y t b$ gene of $C$. acutatum directly from strawberry fruit. The detection of the G143A mutation and discrimination of mutant and wild-type genotypes was successful when the developed protocol was applied using $C$. acutatum DNA extracted directly from artificially inoculated strawberry fruit. The endpoint SNP genotyping analysis generated three distinct clusters according to the genotype or mix of genotypes present on inoculated fruit. DNA samples collected from fruit inoculated with the wild-type $C$. acutatum isolate clustered around the 465 to 510 fluorescence wavelength (FAM fluorescent), whereas DNA collected from fruit inoculated with the G143A-C. acutatum isolate emitted fluorescence in the 533 to 580 wavelength (HEX fluorescent). Mixtures containing wild-type and mutated alleles clustered between homozygous wild-type and

\begin{tabular}{|c|c|}
\hline Isolate & Translated amino acids \\
\hline $96-85 \mathrm{D}(\mathrm{S})$ & YVLPYGQMSLWGATVITNTMSAIPWIGQDIVE \\
\hline $16-450(\mathrm{~S})$ & YVLPYGQMSLWGATVITNTMSAIPWIGQDIVE \\
\hline $10-110(\mathrm{R})$ & YVLPYGQMSLWAATVITNTMSAIPWIGQDIVE \\
\hline $16-440(\mathrm{R})$ & YVLPYGQMSLWAATVITNTMSAIPWIGQDIVE \\
\hline
\end{tabular}

Fig. 3. Amino acid sequence alignment of the partial cytochrome $b$ gene for Colletotrichum gloeosporioides isolates from strawberry. A mutation at codon 143 from glycine to alanine was observed for resistant isolates 10-110 and 16440. Isolates $96-85 \mathrm{D}$ and $16-450$ were sensitive to quinone-outside inhibitor fungicides and had no point mutation in the cytb gene.

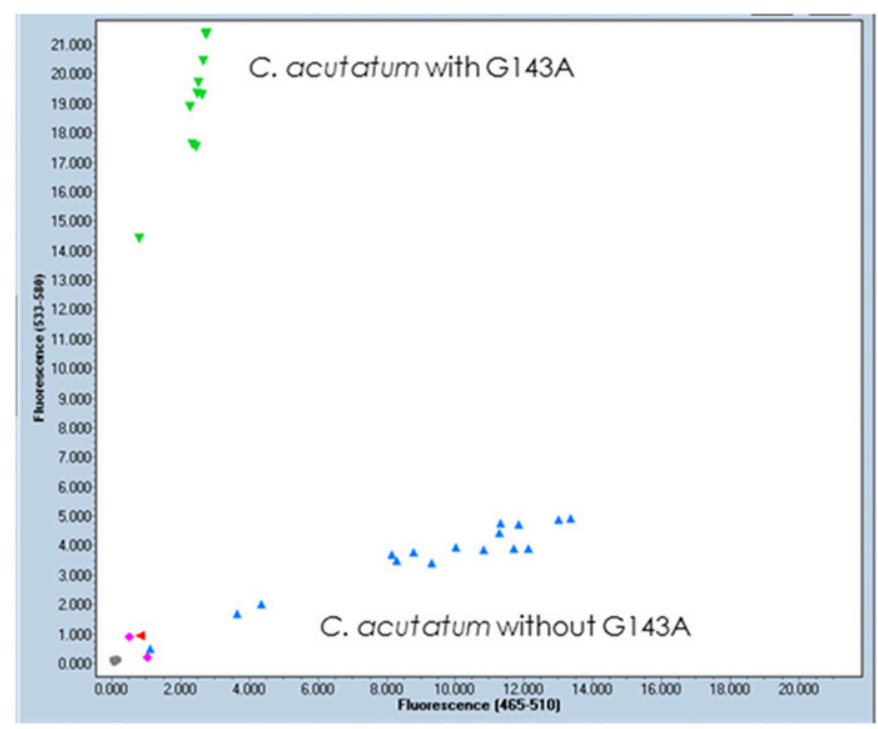

Fig. 4. Endpoint single-nucleotide polymorphism genotyping assay using the primers Ca_QoI_F1 and Ca_QoI_R1, and probes Ca-S-FAM and Ca-R-HEX, for the detection of Colletotrichum acutatum isolates with or without the G143A mutation in the cytochrome $b$ gene, which is associated with quinoneoutside inhibitor resistance. Triangles in the upper left represent $C$. acutatum isolates harboring the G143A mutation, whereas wild-type $C$. acutatum are represented by triangles in the lower center. Gray triangles in the lower left are controls. mutant groups. This genotype is heterozygous and easily distinguished from the other two groups (Fig. 5).

\section{DISCUSSION}

Colletotrichum spp. pathogenic to strawberry cause similar symptoms and may be difficult to distinguish based on morphological and cultural features. In addition, currently used protocols for the detection of mutations associated with fungicide resistance in Colletotrichum spp. are time consuming and labor intensive. In this study, an HRM assay method was developed to rapidly and reliably identify and discriminate Colletotrichum spp. associated with fruit and crown rots in strawberry. Furthermore, the endpoint SNP genotyping assay successfully detected the G143A mutation in the cytb gene of $C$. acutatum and $C$. gloeosporioides. This new alternative to classic techniques is robust enough to rapidly detect the mutations found in field isolates resistant to QoI fungicides.

Accurate identification and differentiation of Colletotrichum at the species level using morphological and cultural characteristics has been an ongoing challenge in strawberry pathology. Such challenges have triggered the development of molecular techniques capable of discriminating Colletotrichum spp. based on certain regions of the DNA (Damm et al. 2012; Grahovac et al. 2012; Weir et al. 2012). Although these techniques have proven to accurately differentiate Colletotrichum spp., they not only require pure fungal cultures but also are labor intensive and time consuming. Thus, a reliable and high-throughput assay was developed to identify and discriminate Colletotrichum spp. directly from symptomatic strawberry tissue.

Since its development, the sensitivity of the HRM assay has been shown to be effective in identifying genetic variations in DNA sequences based on its melting curves (Papavasileiou et al. 2016; Reed et al. 2007). Recent studies reported the use of HRM for the identification and differentiation of Monilinia spp. of peach, Pseudoperonospora spp. of cucurbit and hops, and Phyllosticta spp. of banana (Papavasileiou et al. 2016; Summers et al. 2015; Wong et al. 2013). In addition, researchers have used the HRM assay to detect SNP in genes that are associated with fungicide resistance in plant pathogens such as Botrytis cinerea and Sclerotinia

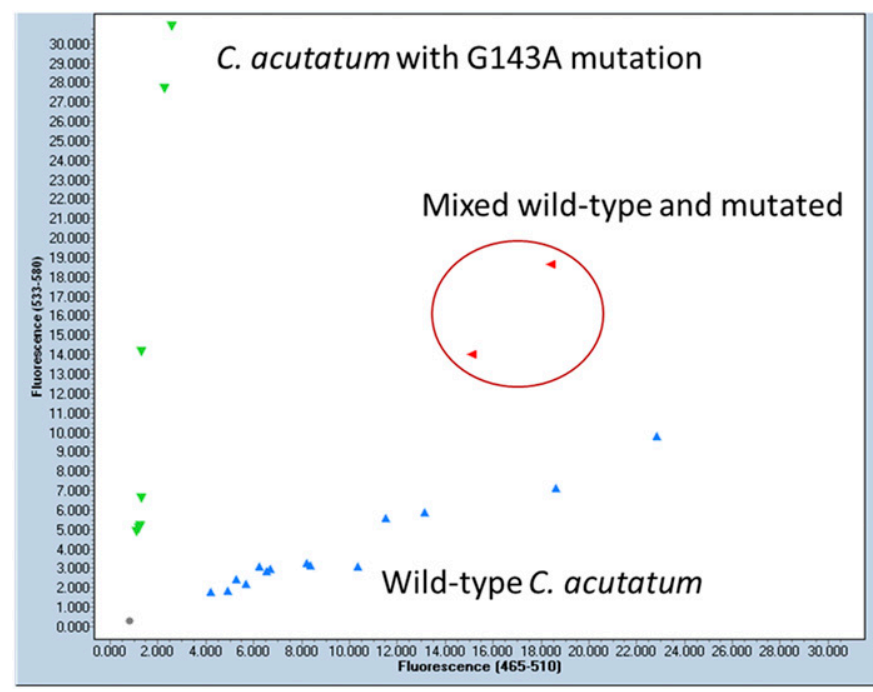

Fig. 5. Endpoint single-nucleotide polymorphism genotyping assay using the primers Ca_QoI_F1 and Ca_QoI_R1, and probes Ca-S-FAM and Ca-S-HEX, for the detection of Colletotrichum acutatum isolates with or without the G143A mutation directly from symptomatic strawberry fruit. Triangles to the left represent $C$. acutatum isolates harboring the G143A mutation, whereas wild-type $C$. acutatum isolates are represented by triangles along the bottom. Triangles within the circle account for mixed wild-type and mutated cytochrome $b$ genes. Gray triangles (lower left) represent negative controls. 
sclerotiorum (Chatzidimopoulos et al. 2014; Lehner et al. 2015; Samaras et al. 2016). In this study, molecular markers were designed based on the ITS region of C. acutatum and C. gloeosporioides from strawberry. This region was chosen because it is conserved among Colletotrichum spp. and reproducibly and accurately differentiated such species (Grahovac et al. 2012; Sreenivasaprasad et al. 1996). HRM markers AcGl-F1 and AcGl-R1 generated consistently different Tm and melting curve profiles, and reliably identified and differentiated DNA of C. acutatum from C. gloeosporioides and C. fragariae, even down to $0.001 \mathrm{ng}$. The approximately $2^{\circ} \mathrm{C}$ difference between the melting curve peaks of Colletotrichum spp. clearly separated isolates pertaining to the $C$. acutatum species complex from those pertaining to the $C$. gloeosporioides species complex.

The HRM assay accuracy was validated in symptomatic strawberry crowns, and strawberry fruit artificially inoculated with C. acutatum, C. gloeosporioides, and C. fragariae. The ability of this assay to discriminate Colletotrichum spp. without the need of fungal isolation and culturing sharply reduces the time and labor involved. Furthermore, the discrimination of Colletotrichum spp. from mixed inoculations was confirmed by the three melting curve profiles generated by the HRM assay. This is important, taking into account that Colletotrichum spp. may co-occur and cause similar symptoms on strawberry fruit. Recent studies have reported the successful performance of the HRM assay using DNA directly from plant tissue. Papavasileiou et al. (2016) developed an HRM assay capable of discriminating Monilinia spp. directly from symptomatic peach fruit tissue, while Samaras et al. (2016) reported the use of the HRM to identify mutations associated with fungicide resistance in $B$. cinerea samples from stone fruit rootstock seedlings and decayed strawberry fruit.

When the HRM analyses was used to detect Colletotrichum spp. from crowns of strawberry plants displaying symptoms of crown and root rots such as wilt and collapse, results differed among Colletotrichum spp. HRM was not able to $\operatorname{detect~C.~acutatum~from~all~}$ the crown samples that tested positive using the standard diagnostic procedures. Decayed tissue is preferred for a successful DNA extraction and further detection. However, even though strawberry plants may display symptoms of $C$. acutatum infection, crown tissue may not yet be decayed. Therefore, the amount of decayed tissue due to $C$. acutatum infections may not have been enough to test positive with the HRM. In contrast, crown infections by $C$. gloeosporioides quickly result in necrotic tissue, which can easily be used for DNA extraction and HRM analysis. Therefore, we suggest that validation of the HRM compared with standard diagnostic procedures was more efficient when detecting $C$. gloeosporioides DNA because plant crowns were evenly decayed.

Resistance to the QoI fungicides has been extensively reported in numerous pathosystems (Amiri et al. 2013; Avila-Adame et al. 2003; Forcelini et al. 2016; Ishii et al. 2001). In strawberry, the emergence of $C$. acutatum and C. gloeosporioides QoI-resistant populations has negatively affected disease management in recent years (Forcelini et al. 2016; Oliveira et al. 2016). Moreover, Forcelini and Peres (2016) reported that QoI resistance in C. acutatum is linked to specific strawberry nurseries across the United States and Canada. Therefore, the early detection of resistant populations is fundamental for strawberry growers to adjust their disease management programs according to the resistance populations present in their fields.

Rapid and high-throughput genotype by sequencing for the detection of SNP linked to fungicide resistance has been an ongoing challenge in molecular genetics. Classic techniques used for gene sequencing such as the Sanger sequencing method have been extensively used for the past decades because of the reduced handling of toxic chemicals (Schuster 2007). In addition, quantitative real-time PCR-based assays have gained attention in the field of molecular diagnostics due to the rapid and simple quantification of nucleic acids, high precision, and because no post-PCR steps are required (Klein 2002). However, such methods are still time consuming and not appropriate for projects involving large populations and small numbers of SNP. Thus, an endpoint SNP genotyping assay was developed to detect a single mutation (G143A) in the $c y t b$ gene of C. acutatum and C. gloeosporioides isolates of strawberry. The molecular markers and allele-specific probes designed accurately and rapidly discriminated mutant genotypes of $C$. acutatum and C. gloeosporioides from the wild-type isolates. A 100-bp region of the cytb gene of C. acutatum and C. gloeosporioides in which the G143A mutation is located was amplified with the designed primer and FAM- and HEX-labeled probe sets. Similar to the HRM and coupled with the advantages of high-throughput sequencing, this probe-based detection method was capable of identifying the G143A mutation from pure fungal cultures and from symptomatic strawberry fruit. This is of particular importance because it rapidly delivers information on the QoI resistance profiles of strawberry fields and allows growers to quickly adjust their disease management programs.

The difficulty in rapidly and accurately identifying and differentiating Colletotrichum spp. infecting strawberry tissues has led to development of the HRM assay presented in this study. This highthroughput and single reaction method quickly and reliable discriminated $C$. acutatum from $C$. gloeosporioides and $C$. fragariae from symptomatic strawberry crowns and fruit. Moreover, results from standard diagnostic clinic procedures confirmed the results generated by the HRM, revealing that such a method could be an important asset to plant disease diagnostic clinics. In the midst of anthracnose outbreaks in strawberry nurseries and fields due to the selection of QoI-resistant C. acutatum and C. gloeosporioides populations, rapid diagnostic tools are necessary to identify resistance in large numbers of isolates. Thus, the PCR-based endpoint SNP genotyping assay was developed in this study to quickly detect the G143A mutation in the $c y t b$ gene, which is associated with QoI resistance in $C$. acutatum and $C$. gloeosporioides of strawberry. The results of this study suggest that the HRM and endpoint SNP genotyping analyses are robust, accurate, and high-throughput tools that can be implemented in plant disease diagnostic clinics for the rapid and accurate identification of Colletotrichum spp. and for tracking of QoI resistance in strawberry nurseries and production fields.

\section{ACKNOWLEDGMENTS}

We thank J. Mertely, N.-Y. Wang, M. V. Marin, and L. G. Cordova for technical support.

\section{LITERATURE CITED}

Amiri, A., Heath, S., and Peres, N. 2013. Phenotypic characterization of multifungicide resistance in Botrytis cinerea isolates from strawberry fields in Florida. Plant Dis. 97:393-401.

Avila-Adame, C., Olaya, G., and Köller, W. 2003. Characterization of Colletotrichum graminicola isolates resistant to strobilurin-related QoI fungicides. Plant Dis. 87:1426-1432.

Bartlett, D. W., Clough, J. M., Godwin, J. R., Hall, A. A., Hamer, M., and ParrDobrzanski, B. 2002. The strobilurin fungicides. Pest Manage. Sci. 58: 649-662.

Chatzidimopoulos, M., Ganopoulos, I., Vellios, E., Madesis, P., Tsaftaris, A., and Pappas, A. C. 2014. Development of a two-step high-resolution melting (HRM) analysis for screening sequence variants associated with resistance to the QoIs, benzimidazoles and dicarboximides in airborne inoculum of Botrytis cinerea. FEMS Microbiol. Lett. 360:126-131.

Damm, U., Cannon, P., Woudenberg, J., and Crous, P. 2012. The Colletotrichum acutatum species complex. Stud. Mycol. 73:37-113.

De la Vega, F. M., Lazaruk, K. D., Rhodes, M. D., and Wenz, M. H. 2005. Assessment of two flexible and compatible SNP genotyping platforms: TaqMan ${ }^{\circledR}$ SNP Genotyping Assays and the SNPlex ${ }^{\text {TM }}$ Genotyping System. Mutat. Res. 573:111-135.

Forcelini, B., and Peres, N. 2016. Monitoring Colletotrichum acutatum resistance to quinone- outside inhibitor fungicides in strawberry. (Abstr) Phytopathology 106:S4.73. 
Forcelini, B. B., Rebello, C. S., Wang, N.-Y., and Peres, N. 2018. Fitness, competitive ability and mutation stability of isolates of Colletotrichum acutatum from strawberry resistant to QoI fungicides. Phytopathology 108:462-468. link

Forcelini, B. B., Seijo, T. E., Amiri, A., and Peres, N. A. 2016. Resistance in strawberry isolates of Colletotrichum acutatum from Florida to quinoneoutside inhibitor fungicides. Plant Dis. 100:2050-2056.

Gisi, U., Sierotzki, H., Cook, A., and McCaffery, A. 2002. Mechanisms influencing the evolution of resistance to Qo inhibitor fungicides. Pest Manage. Sci. 58:859-867.

Gopaul, K. K., Sells, J., Lee, R., Beckstrom-Sternberg, S. M., Foster, J. T., and Whatmore, A. M. 2014. Development and assessment of multiplex high resolution melting assay as a tool for rapid single-tube identification of five Brucella species. BMC Res. Notes 7:903.

Grahovac, M., Indic, D., Vukovic, S., Hrustc, J., Gvozdenac, S., Mihajlovic, M., and Tanovic, B. 2012. Morphological and ecological features as differentiation criteria for Colletotrichum species. Liet. Zemdirbyste Mokslinio Tyrimo Inst. Darb. 99:189-196.

Hu, M.-J., Grabke, A., Dowling, M. E., Holstein, H. J., and Schnabel, G. 2015. Resistance in Colletotrichum siamense from peach and blueberry to thiophanate-methyl and azoxystrobin. Plant Dis. 99:806-814.

Ishii, H., Fraaije, B., Sugiyama, T., Noguchi, K., Nishimura, K., Takeda, T., Amano, T., and Hollomon, D. 2001. Occurrence and molecular characterization of strobilurin resistance in cucumber powdery mildew and downy mildew. Phytopathology 91:1166-1171.

Klein, D. 2002. Quantification using real-time PCR technology: Applications and limitations. Trends Mol. Med. 8:257-260.

Legard, D. E., Ellis, M., Chandler, C. K., and Price, J. F. 2003. Integrated management of strawberry diseases in winter fruit production areas. Pages 111-124 in: The Strawberry: A Book for Growers. N. F. Childers, ed. Dr. Norman N. Childers Publications, Gainesville, FL.

Lehner, M., Paula Júnior, T., Silva, R., Vieira, R., Carneiro, J., Schnabel, G., and Mizubuti, E. 2015. Fungicide sensitivity of Sclerotinia sclerotiorum: A thorough assessment using discriminatory dose, $\mathrm{EC}_{50}$, high-resolution melting analysis, and description of new point mutation associated with thiophanate-methyl resistance. Plant Dis. 99:1537-1543.

MacKenzie, S., Peres, N. A., Barquero, M., Arauz, L., and Timmer, L. 2009. Host range and genetic relatedness of Colletotrichum acutatum isolates from fruit crops and leatherleaf fern in Florida. Phytopathology 99:620-631.

Mertely, J. C., Forcelini, B. B., and Peres, N. A. 2017a. Anthracnose fruit rot of strawberry. Online publication. Electronic Data Information Source, University of Florida, Institute of Food and Agricultural Sciences. http:// edis.ifas.ufl.edu/pp130

Mertely, J. C., Forcelini, B. B., and Peres, N. A. 2017b. Root necrosis of strawberry caused by Colletotrichum acutatum. Online publication. Electronic Data Information Source, University of Florida, Institute of Food and Agricultural Sciences. http://edis.ifas.ufl.edu/pp128

Mertely, J. C., Seijo, T. E., and Peres, N. A. 2015. Evaluation of products for anthracnose and Botrytis fruit rot control in annual strawberry, 2013-14. Plant Dis. Manage. Rep. 9:SMF007.

Miles, T. D., Martin, F. N., and Coffey, M. D. 2015. Development of rapid isothermal amplification assays for detection of Phytophthora spp. in plant tissue. Phytopathology 105:265-278.

Noh, Y.-H., Lee, S., Whitaker, V. M., Cearley, K. R., and Cha, J.-S. 2017. A high-throughput marker-assisted selection system combining rapid DNA extraction high-resolution melting and simple sequence repeat analysis: Strawberry as a model for fruit crops. J. Berry Res. 7:23-31.

Oliveira, M., Chamorro, M., and Peres, N. 2016. Resistance of Colletotrichum gloeosporioides from strawberry to azoxystrobin and reduced-sensitivity to thiophanate-methyl. (Abstr) Phytopathology 106:S4.72.
Papavasileiou, A., Madesis, P. B., and Karaoglanidis, G. S. 2016. Identification and differentiation of Monilinia species causing brown rot of pome and stone fruit using high-resolution melting (HRM) analysis. Phytopathology 106:1055-1064

Peres, N. A., Oliveira, M. S., and MacKenzie, S. J. 2017. Colletotrichum crown rot (anthracnose crown rot) of strawberries. Online publication. Electronic Data Information Source, University of Florida, Institute of Food and Agricultural Sciences. http://edis.ifas.ufl.edu/pp156

Peres, N. A., Timmer, L. W., Adaskaveg, J. E., and Correll, J. C. 2005. Lifestyles of Colletotrichum acutatum. Plant Dis. 89:784-796.

Rasheed, A., Hao, Y., Xia, X., Khan, A., Xu, Y., Varshney, R. K., and He, Z. 2017. Crop breeding chips and genotyping platforms: Progress, challenges, and perspectives. Mol. Plant 10:1047-1064

Reed, G. H., Kent, J. O., and Wittwer, C. T. 2007. High-resolution DNA melting analysis for simple and efficient molecular diagnostics. Pharmacogenomics 8:597-608.

Samaras, A., Madesis, P., and Karaoglanidis, G. S. 2016. Detection of $s d h B$ gene mutations in SDHI-resistant isolates of Botrytis cinerea using high resolution melting (HRM) analysis. Front. Microbiol. 7:1815.

Schuster, S. C. 2007. Next-generation sequencing transforms today's biology. Nat. Methods 5:16-18.

Shen, G.-Q., Abdullah, K. G., and Wang, Q. K. 2009. The TaqMan method for SNP genotyping. Pages 293-306 in: Single Nucleotide Polymorphisms: Methods and Protocols. Methods in Molecular Biology. A. A. Komar, ed. Humana Press, New York.

Smith, B. J. 1998a. Anthracnose fruit rot (black spot). Pages 31-33 in: Compendium of Strawberry Diseases. J. L. Maas, ed. The American Phytopathological Society, St. Paul, MN.

Smith, B. J. 1998b. Anthracnose crown rot. Pages 42-48 in: Compendium of Strawberry Diseases. J. L. Maas, ed. The American Phytopathological Society, St. Paul, MN.

Smith, B. J., and Black, L. L. 1990. Morphological, cultural, and pathogenic variation among Colletotrichum species isolated from strawberry. Plant Dis. 74:69-76.

Sreenivasaprasad, S., Sharada, K., Brown, A., and Mills, P. 1996. PCR-based detection of Colletotrichum acutatum on strawberry. Plant Pathol. 45: 650-655.

Summers, C. F., Adair, N. L., Gent, D. H., McGrath, M. T., and Smart, C. D. 2015. Pseudoperonospora cubensis and P. humuli detection using speciesspecific probes and high definition melt curve analysis. Can. J. Plant Pathol. 37:315-330.

Taheri, S., Abdullah, T. L., Jain, S. M., Sahebi, M., and Azizi, P. 2017. TILLING, high- resolution melting (HRM), and next-generation sequencing (NGS) techniques in plant mutation breeding. Mol. Breed. 37: 40 .

Turechek, W. W., Peres, N. A., and Werner, N. A. 2006. Pre-and post-infection activity of pyraclostrobin for control of anthracnose fruit rot of strawberry caused by Colletotrichum acutatum. Plant Dis. 90:862-868.

Van der Aa, H., Noordeloos, M., and Gruyter, J. d. 1990. Species concepts in some larger genera of the Coelomycetes. Stud. Mycol. 32:3-19.

Vossen, R. H., Aten, E., Roos, A., and den Dunnen, J. T. 2009. High-Resolution Melting Analysis (HRMA)-More than just sequence variant screening. Hum. Mutat. 30:860-866.

Weir, B., Johnston, P., and Damm, U. 2012. The Colletotrichum gloeosporioides species complex. Stud. Mycol. 73:115-180.

Wong, M. H., Henderson, J., and Drenth, A. 2013. Identification and differentiation of Phyllosticta species causing freckle disease of banana using high resolution melting (HRM) analysis. Plant Pathol. 62: $1285-1293$ 